\title{
LIDERANÇA ESTRATÉGICA E CRIAÇÃO DE VALOR
}

\author{
W. Glenn Rowe \\ Doutor em Administração pela Texas A\&M University, Professor e Reitor Associado do Programa de Pós-Graduação \\ e Pesquisa da Faculty of Business Administration da Memorial University of Newfoundland (Canadá). \\ E-mail: growe@mun.ca
}

\begin{abstract}
RESUMO
A criação de valor tanto nas organizações recém-criadas quanto nas já estabelecidas é uma tarefa complexa e desafiadora. A liderança estratégica cria condições favoráveis para esse processo e para a maximização do retorno sobre o investimento. A liderança gerencial provavelmente conseguirá, no máximo, retornos equivalentes à média dos retornos. As organizações lideradas por visionários que não possuem apoio de uma liderança gerencial sólida podem perder seus recursos até mais rapidamente do que as dirigidas por líderes gerenciais. Este artigo define liderança estratégica e diferencia os conceitos de liderança estratégica, visionária e gerencial. Além disso, analisa os diferentes vínculos entre esses três tipos de liderança e a criação de valor. Quando as organizações restabelecem o controle estratégico e permitem o desenvolvimento de um grupo de líderes estratégicos, eles serão fonte de maximização do retorno sobre o investimento. O resultado será a criação de valor para os funcionários, clientes, fornecedores e acionistas.
\end{abstract}

\begin{abstract}
Wealth creation in entrepreneurial and established organizations is a complex, challenging task in today's global and technologically advancing business environment. Strategic leadership enhances the wealthcreation process in entrepreneurial and established organizations, and leads to above-average returns. On the other hand, managerial leadership will likely lead to average returns at best, but is most likely to achieve below-average returns and destroy wealth. Organizations led by visionaries who are not properly supported by strong managerial leadership may destroy wealth even more quickly than organizations led by managerial leaders. This article defines strategic leadership, differentiates among the concepts of strategic, visionary, and managerial leadership, and examines the differential links between the three types of leadership and wealth creation. When organizations restore strategic control and allow the development of a critical mass of strategic leaders, these leaders will be a source of above-average returns. The result will be wealth creation for the employees, customers, suppliers, and shareholders of entrepreneurial and established organizations.
\end{abstract}

\section{PALAVRAS-CHAVE}

Estratégia, liderança estratégica, liderança visionária, liderança gerencial, criação de valor.

\section{KEY WORDS}

Strategy, strategic leadership, visionary leadership, managerial leadership, wealth creation. 
"Sem uma liderança estratégica eficiente, a probabilidade de uma empresa apresentar boa performance ao mesmo tempo em que enfrenta os desafios da economia mundial diminui drasticamente." R. Duane Ireland e Michael A. Hitt (1999)

\section{INTRODUÇÃO}

Como executivo principal da Starbucks, Howard Schultz adotou estratégias que mudaram completamente o mercado de café no qual sua empresa atua (Mintzberg et al., 1998). Quando a comprou do proprietário original, em 1987, havia 6 lojas e 100 funcionários. Em 1996, a Starbucks tinha 1.300 lojas e 25 mil funcionários e atuava na América do Norte e no Japão. Até o final do ano fiscal de 1999, a Starbucks tinha 2.498 lojas (363 delas eram franqueadas e as restantes pertencentes à empresa) e 35.620 funcionários e já atuava no Canadá e no Reino Unido. As vendas e os lucros aumentaram mais de $50 \%$ anualmente por seis anos consecutivos, e o valor das ações, dez vezes de 1992 até 1997. Apesar de as vendas e lucros terem diminuído a partir de 1997, ainda continuaram expressivos, aumentando 29\% e 50\% respectivamente de 1998 a 1999. A filosofia de Schultz ilustra a postura de um líder estratégico. Sua prioridade é zelar por seus funcionários, uma vez que eles são os responsáveis por estabelecer uma relação estreita com os clientes. Schultz acredita que, se seus funcionários fizerem bem isso, a Starbucks cumprirá sua missão de "educar" os clientes sobre as vantagens de beber café sofisticado e criar uma atmosfera que atrairá as pessoas a suas lojas, "transmitindo-lhes uma sensação de encanto e fantasia em meio a sua vida atribulada" (Schultz e Yang, 1997; Starbucks, 1997). Além disso, a empresa proporcionara um crescimento, em longo prazo, no valor para o acionista. De 1992 - ano em que a Starbucks abriu capital - a 1998, seu Valor Adicionado ao Mercado (VAM) aumentou de US\$ 0,41 bilhão para US\$ 4,26 bilhões, representando um crescimento no patrimônio do acionista de US\$3,85 bilhões (Walbert, 1995; Ross, 1996, 1997, 1998, 1999). Tal valorização reflete uma empresa comandada por um líder estratégico.

Liderança estratégica é a capacidade de influenciar outras pessoas a tomar, de forma voluntária e rotineira, decisões que aumentem a viabilidade em longo prazo da organização, ao mesmo tempo em que mantêm a estabilidade financeira em curto prazo. A liderança visionária tem o futuro em vista e implica correr riscos. A percepção de líderes visionários sobre si próprios não é vinculada à organização e, sob sua liderança, o controle organizacional é mantido por meio da socialização e da conformidade com um conjunto de normas, valores e opiniões em comum. A liderança gerencial envolve, além da estabilidade e ordem, a manutenção do status quo. Os líderes gerenciais sentem-se melhor quando lidam com atividades rotineiras e têm o curto prazo em vista (ver Quadro 1).

Os resultados excepcionais de VAM alcançados pela Microsoft (US\$ 420 bilhões), GE (US\$ 360 bilhões) e Coca-Cola (US\$ 169 bilhões) desde a criação dessas empresas até o final de 1998 sugerem que Bill Gates e Jack Welch são líderes estratégicos, à semelhança de Robert Goizueta, já falecido (A conversation, 1995; Sellers, 1996; Morris, 1995). Por outro lado, a contínua desvalorização do patrimônio dos acionistas por empresas como a General Motors (VAM negativo de US\$17,9 bilhões ao final de 1998) e o Kmart (VAM negativo de US\$ 1 bilhão ao final de 1998) indica a falta de liderança estratégica. A falta de liderança estratégica e o predomínio da liderança gerencial são problemas importantes enfrentados pelas organizações e continuarão persistindo, a não ser que membros do conselho e executivos entendam a questão e as diferenças entre líderes gerenciais, visionários e estratégicos.

Liderança é um tema extremamente amplo e está desgastado entre alguns grupos (Gardner e Avolio, 1998; Chen e Meindl, 1991; Kerr e Jermier, 1978; Meindl et al., 1985; Meindl, 1990). Alguns especialistas, entretanto, acreditam que líderes fazem a diferença. Os pesquisadores Sayan Chatterjee, Michael Lubatkin e William Schulze argumentam: "Nossa teoria de campo, pesquisas e prática de ensino baseiam-se na intuição de que a administração é importante: as empresas, por meio de atitudes calculadas, podem proteger seus lucros de forças de mercado, o que é valioso para os investidores" (Hill e Wetlaufer, 1998; Chatterjee et al., 1999).

Acreditamos que a liderança estratégica é o melhor estilo de liderança para que isso possa ser conseguido. Ireland e Hitt (1999) definem liderança estratégica como: "a capacidade de prever, imaginar, manter a flexibilidade, pensar estrategicamente e trabalhar com outras pessoas para dar início às mudanças que proporcionarão um futuro viável para a empresa."

Este artigo apresenta uma definição diferente de liderança estratégica e diferencia os conceitos de liderança gerencial, visionária e estratégica. Algumas restrições da liderança estratégica são discutidas. Por fim, será apresentado o impacto das lideranças gerenciais, visionárias e estratégicas na criação de valor.

\section{DEFINIÇÃO DE LIDERANÇA ESTRATÉGICA}

A palavra grega strategos refere-se a um general no comando de um exército. Estratégia relaciona-se às habilidades psicológicas e comportamentais que moti- 
Quadro 1 - Liderança estratégica, visionária e gerencial

\begin{tabular}{|c|c|c|}
\hline Líderes estratégicos & Líderes visionários & Líderes gere \\
\hline $\begin{array}{l}\text { - Usam padrões de pensamento } \\
\text { linear e não linear } \\
\text { - Acreditam na adoção de } \\
\text { estratégias, isto é, suas decisões } \\
\text { estratégicas fazem diferença em } \\
\text { suas organizações e ambiente } \\
\text { de trabalho }\end{array}$ & 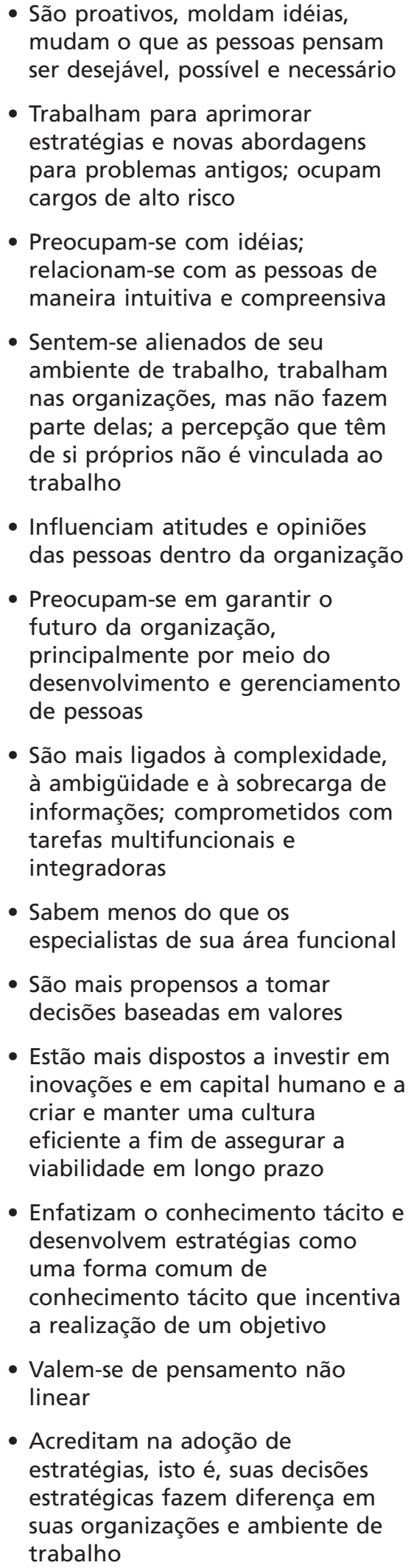 & 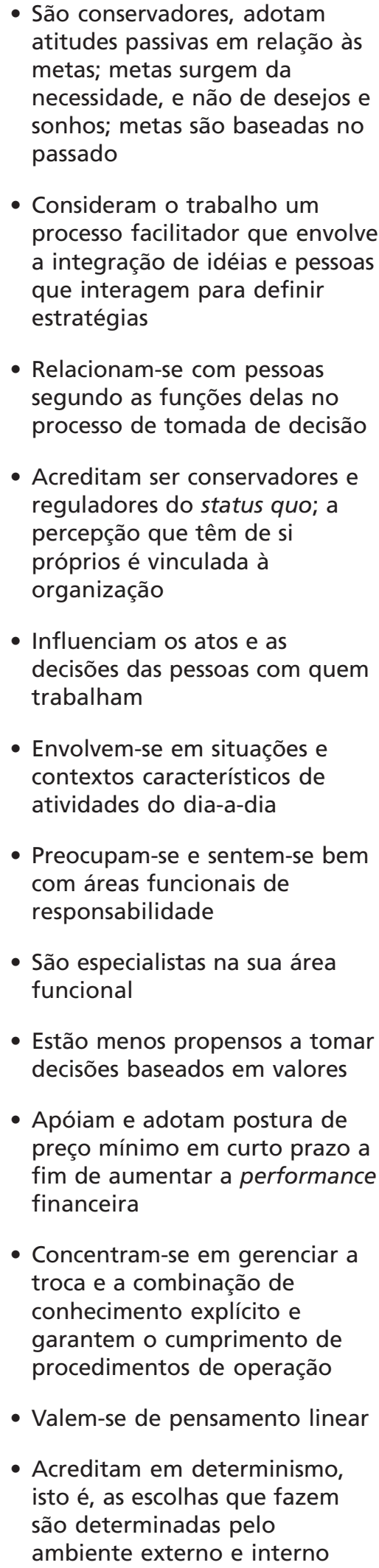 \\
\hline
\end{tabular}


vam um general: a arte do general. Até 450 a.C., essa definição evoluiu, a fim de incluir habilidades gerenciais, como administração, liderança, oratória e autoridade. Por volta de 330 a.C., o termo strategos passou a significar a capacidade de empregar forças para vencer forças inimigas e desenvolver um sistema unificado de governança global (Evered, 1980; Quinn, 1980; Mintzberg e Quinn, 1996). Neste artigo, a liderança estratégica é definida como a habilidade de influenciar outras pessoas a tomar, de forma voluntária e rotineira, decisões que aumentem a viabilidade em longo prazo da organização, ao mesmo tempo em que mantêm a estabilidade financeira em curto prazo.

\section{INFLUENCIAR FUNCIONÁRIOS}

\section{A TOMAR, VOLUNTARIAMENTE, DECISÕES QUE AJUDEM A ORGANIZAÇÃO É O ASPECTO}

\section{MAIS IMPORTANTE DA}

\section{LIDERANÇA ESTRATÉGICA.}

Essa definição é diferente da estabelecida por Ireland e Hitt (1999), já que inclui, explicitamente, o conceito de tomada de decisões voluntárias e concentra-se tanto no presente quanto no futuro. Gerentes e funcionários tomam decisões todos os dias quando interagem entre si e com os grupos de poder, principalmente os clientes, os fornecedores e as comunidades em que atuam. Essas decisões estão de acordo com a direção estratégica da organização? Vão aumentar a viabilidade futura da organização e a estabilidade financeira em curto prazo? Confiar em gerentes e funcionários para tomar decisões que beneficiem a organização significa que a alta gerência não fará tantos esforços no monitoramento e controle e terá mais capacidade para inteirar-se do que a organização necessita, tanto em curto quanto em longo prazo. Por outro lado, mesmo que gerentes e empregados realmente conheçam as direções estratégicas da organização, podem, por negligência, tomar decisões que prejudiquem a organização. Além disso, se conhecerem as direções estratégicas e quiserem, de alguma forma, lesar a organização, podem tomar, voluntariamente, decisões que a prejudiquem. Isso requer maior esforço para monitorar e controlar e menor esforço para o que necessita ser feito com vistas à viabilidade em curto e longo prazos. Influenciar funcionários a tomar, voluntariamente, decisões que ajudem a organização é o aspecto mais importante da liderança estratégica. Segundo Tichy e Cohen (1997, p. 106): "Quando não se pode controlar, dar ordens ou monitorar, a única coisa que nos resta é confiar. Isso significa que os líderes precisam ter certeza de que as pessoas em quem estão confiando têm valores para tomar as decisões e atitudes que eles querem."

A definição de liderança estratégica pressupõe a habilidade de influenciar subordinados, pares e superiores. Também presume que o líder entenda o processo de estratégia emergente, que alguns autores consideram mais importante do que o processo de planejamento estratégico (Mintzberg, 1987a, 1987b). As decisões e as atitudes tomadas voluntariamente por gerentes e funcionários todos os dias acabam por determinar a estratégia emergente. Líderes estratégicos entendem esse processo e valem-se dele para garantir a viabilidade futura de suas organizações. A liderança estratégica pressupõe uma visão comum do que uma organização deve ser, para que a tomada de decisões rotineiras ou o processo de estratégia emergente sejam coerentes com essa visão. Isso implica a existência de um acordo entre os gerentes corporativos e os gerentes de divisões sobre as oportunidades e ameaças, dados os recursos e capacidade da organização (Barney, 1997). A liderança estratégica pressupõe que a liderança visionária e a gerencial podem coexistir e que estão unidas, em sinergia, pela liderança estratégica. Também presume a habilidade dos líderes estratégicos de mudar suas organizações para que haja uma mudança no ambiente em que suas organizações atuam (Hitt et al., 2001).

Nas duas seções seguintes, serão discutidos os conceitos de liderança gerencial e de liderança visionária. Grande parte dessa discussão é baseada no clássico artigo de Zaleznik (1977).

\section{LIDERANÇA GERENCIAL}

A maioria dos executivos exerce a liderança gerencial. Por diversas razões, as organizações treinam seus funcionários implícita e explicitamente para serem líderes gerenciais. Organizações empresariais diversificadas em vários negócios tendem a fazer isso. Governos treinam ainda mais seus funcionários para serem líderes gerenciais do que as empresas, devido à prestação de contas, ao grau de diversificação, à questão da reeleição e, para a maioria dos governos, ao enorme volume da dívida. Esses fatores levam à imposição de um sistema de controle financeiro que estimula o uso da liderança gerencial e desestimula as lideranças estratégica e visionária. Há pessoas capazes de exercer ambas as lideranças - estratégica e visionária - em tais organizações, mas a natureza destas as desestimula.

Líderes gerenciais adotam atitudes impessoais e passivas em relação às metas. Metas surgem da necessidade, e não de desejos e sonhos, baseiam-se na origem 
das organizações e estão intimamente ligadas à história e à cultura da organização (Zaleznik, 1977). Segundo Jack Welch e Robert Goizueta, já falecido, a insensibilidade em relação ao passado é necessária (Morris, 1995). Líderes gerenciais são sensíveis ao passado.

Líderes gerenciais consideram o trabalho um processo que permite a interação de idéias e pessoas, a fim de definir estratégias e tomar decisões. Durante esse processo, negociam, barganham e usam recompensas, punições ou outras formas de coerção. Eles relacionamse com pessoas de acordo com seus papéis no processo de tomada de decisão e com a maneira pela qual as coisas são feitas. Líderes gerenciais podem não ter empatia e podem procurar envolver-se com outras pessoas, mas mantêm um baixo comprometimento emocional nesses relacionamentos. Precisam de ordem, e não do caos potencialmente inerente às relações humanas. Eles vêem-se como reguladores e conservadores do status quo de suas organizações e identificam-se pessoalmente com ele. Fortalecer e perpetuar suas instituições faz bem ao ego desses gerentes. Por exemplo, se as pessoas sentem que fazem parte de uma instituição e que contribuem para o bem-estar desta, podem achar que uma missão em sua vida foi cumprida e sentir-se gratificadas por terem atingido um objetivo. Essa gratificação pode ultrapassar as recompensas materiais e satisfazer desejos de credibilidade pessoal. Quando isso ocorre, os líderes gerenciais podem sentir-se desnorteados e angustiados depois de uma reestruturação na organização em que trabalharam a vida toda (Zaleznik, 1977).

Líderes gerenciais influenciam somente as atitudes e decisões daqueles que com eles trabalham (Hosmer, 1982). Estão envolvidos em situações e contextos característicos de atividades rotineiras (Schendel, 1989), comprometendo-se mais e sentindo-se melhor em áreas funcionais de responsabilidades. Têm mais conhecimento de suas áreas funcionais (Hambrick, 1989). Os líderes gerenciais podem tomar decisões que não estejam sujeitas a restrições baseadas em valores (Hosmer, 1982), o que não significa que não tenham moral e ética. Em se tratando de gerentes, no entanto, podem não incluir valores no seu processo de tomada de decisão devido a pressões como o controle financeiro. Esses líderes apóiam e adotam postura de preço mínimo em curto prazo a fim de aumentar a performance financeira em curto prazo (Hill e Hoskisson, 1987; Hoskisson e Hitt, 1994; Zaleznik, 1990). Eles concentram-se em administrar a troca e a interação de conhecimentos explícitos e também em garantir que os procedimentos operacionais padronizados sejam cumpridos. Valemse de um processo de pensamento linear. Por fim, líderes gerenciais acreditam em determinismo: fazem o que é determinado pelos ambientes interno e externo da organização (ver Trigg, 1996; Child, 1972;
Mintzberg et al., 1998). A liderança gerencial é parecida em alguns pontos com a liderança transacional (Bass, 1985; Yukl, 1994).

É preciso destacar que ser um líder gerencial não é ruim e que as organizações necessitam desse tipo de liderança. É possível, entretanto, que um número excessivo de organizações seja comandado por esses líderes e que eles não criem valor. Líderes gerenciais vão, na melhor das hipóteses, conservar o valor. Podem, porém, provocar redução no valor em longo prazo, se o seu estilo predomina na organização.

\section{LIDERANÇA VISIONÁRIA}

A liderança visionária tem sido divulgada como a cura de muitos males que afetam as organizações (Conger, 1991; Nathan, 1996). Infelizmente, os líderes visionários não são aceitos facilmente pelas organizações e, se não tiverem o apoio dos líderes gerenciais, podem ser inadequados. Além disso, recorrer a líderes visionários pode representar riscos. A liderança visionária exige autoridade para influenciar o pensamento e as atitudes das pessoas, o que significa delegar poderes e implica correr riscos em várias dimensões. Há o risco de equiparar poder e a habilidade de

\section{UM LÍDER ESTRATÉGICO}

\section{PROVAVELMENTE CRIARÁ}

\section{MAIS VALOR QUE A COMBINAÇÃO DE UM LÍDER VISIONÁRIO E DE UM GERENCIAL.}

atingir resultados imediatos, o risco de perder o autocontrole no desejo de conseguir mais poder e o risco de enfraquecer o desenvolvimento de líderes gerenciais, que ficam ansiosos com a desordem que a presença de líderes visionários pode causar. As atitudes dos líderes visionários em relação às metas opõem-se às dos líderes gerenciais. Líderes visionários são relativamente mais proativos, moldando idéias em vez de se oporem a elas. Exercem influência de uma maneira que determina a direção que a organização deve tomar. Eles criam imagens e suscitam expectativas, alterando humores e definindo desejos específicos e objetivos. Influenciam o que as pessoas acreditam ser possível, desejável e necessário. Líderes visionários esforçamse para aprimorar escolhas e abordagens novas para problemas antigos. Provocam agitação no ambiente. Trabalham em posições de alto risco e buscam negóci- 
os arriscados, especialmente quando as recompensas são altas. Preocupam-se com idéias, relacionam-se com as pessoas de maneira intuitiva e compreensiva. Concentram sua atenção no significado dos acontecimentos e decisões. Quando líderes visionários estão no comando, as relações humanas tornam-se mais turbulentas, intensas e até desorganizadas, o que pode intensificar a motivação individual e gerar resultados inesperados, tanto negativos quanto positivos. Sentem-se alienados de seu ambiente de trabalho e, às vezes, de outras pessoas; trabalham nas organizações, mas não se sentem parte delas. A percepção que têm de si próprios não está vinculada ao trabalho, a papéis ou a que instituição estão ligados, mas, sim, ao sentido de identidade que criaram. Essa identidade pode ser resultado de acontecimentos importantes de sua vida (Zaleznik, 1977).

Os líderes visionários influenciam as opiniões e atitudes de outras pessoas dentro da organização (Hosmer, 1982). Preocupam-se em garantir o futuro desta, por meio do desenvolvimento e gerenciamento de pessoas (Schendel, 1989). São ligados à complexidade, à ambigüidade e à sobrecarga de informações. Sua tarefa é multifuncional e têm muito mais tarefas integradoras e complexas (Hambrick, 1989; Mintzberg, 1973). Devido a isso, acabam por saber menos do que os especialistas de área funcional sobre cada uma das muitas áreas pelas quais são responsáveis (Hambrick, 1989).

Visionários são mais propensos a tomar decisões baseadas em valores (Evans, 1997; Hosmer, 1982; Sooklal, 1991; Zaleznik, 1977) e mais dispostos a in- meio da socialização, do compartilhamento de visões e da conformidade com um conjunto de normas, valores e opiniões em comum. De certa forma, a liderança visionária é parecida com o componente inspirador da liderança transformacional (Bass, 1985; Yukl, 1994). As organizações precisam da liderança visionária para garantir a viabilidade em longo prazo; entretanto, organizações lideradas por visionários, sem a influência restritiva de líderes gerenciais, correm mais riscos de fracassar em curto prazo do que as comandadas por líderes gerenciais. Líderes visionários estão dispostos a arriscar; assim, podem criar valor. Visionários também podem, porém, investir mais em seus objetivos do que a garantia de retorno e, dessa forma, destruir valor se não tiverem suas ações moderadas por líderes gerenciais.

Uma solução para as organizações seria a integração de líderes gerenciais e visionários, devendo os visionários terem mais influência do que os gerenciais (Kotter, 1990). Uma solução melhor seria ter um indivíduo com características visionárias e gerenciais. Zaleznik $(1977,1990)$ argumenta, todavia, que visionários e gerentes são diferentes e que ninguém pode exercer esses dois estilos de liderança simultaneamente. Ele sugere que líderes visionários e gerenciais estão em extremos opostos de um continuum e que tentar exercer ambas as lideranças simultaneamente pode levar um indivíduo a ficar estagnado no centro desse continuum, acabando por não exercer nenhum estilo de liderança (ver Figura 1).

\section{Figura 1 - Continuum de Zaleznik de liderança visionária e gerencial}

vestir em inovações, em capital humano e na criação e manutenção de uma cultura eficiente, a fim de assegurar a viabilidade em longo prazo (Hoskisson e Hitt, 1994). Líderes visionários concentram-se em conhecimento tácito e desenvolvem estratégias como uma forma comum de conhecimento tácito que incentiva a conquista de um objetivo (ver Polanyi, 1966; Reed e DeFillippi, 1990; Nelson e Winter, 1982; Itami, 1987; Kotter e Heskett, 1992; Ouchi e Maguire, 1975; Schein, 1993). Valem-se de pensamento não linear e acreditam na adoção de estratégias, ou seja, acreditam que suas decisões estratégicas fazem diferença para as organizações e afetam o ambiente de trabalho.

A liderança visionária é voltada para o futuro e preocupa-se em correr riscos, além disso, líderes visionários não dependem de suas organizações para conceber uma percepção sobre si próprios. Sob a liderança de visionários, o controle organizacional é mantido por
Essa perspectiva não é despropositada se considerarmos o que se segue. Líderes gerenciais procuram estabilidade, ordem e a manutenção do status quo; líderes visionários buscam criatividade, inovação, desordem e a mudança do status quo. Líderes gerenciais acham difícil aceitar o fato de que uma organização possa passar por uma fase transitória impelida por uma visão de futuro. A organização que esses líderes ajudaram a construir e que é parte da sua identidade está sendo reconstruída como algo que os desagrada, pois o futuro é incerto. Sob o prisma de líderes visionários, a instabilidade seria mais normal do que a estabilidade proposta pela liderança gerencial. Na verdade, o ambiente que está sendo criado pelas forças globais e tecnológicas de hoje é de mudança e complexidade. Kotter (1990) sugere que as organizações precisam de líderes para introduzir mudanças e de gerentes para lidar com a complexidade. 
Ao contrário de Zaleznik, acreditamos que as lideranças visionária e gerencial são dois construtos separados. É necessário reiterar e ressaltar que ambas as lideranças são vitais para a viabilidade em longo prazo e a estabilidade financeira em curto prazo. É possível que as lideranças visionária e gerencial coexistam; entretanto, a visionária deve pesar mais que a gerencial. Uma organização seria, contudo, mais viável em longo prazo e poderia manter sua estabilidade financeira em curto prazo se a liderança estratégica prevalecesse nessa organização. Para estabelecermos o conceito de liderança estratégica, argumentamos que a liderança visionária e a gerencial devem ser vistas como continua separados. A Figura 2 ilustra a liderança estratégica como uma integração, em sinergia, da liderança visionária e da liderança gerencial, o que não é possível sob a visão de Zaleznik (1977).

\section{LIDERANÇA ESTRATÉGICA}

Líderes estratégicos diferem dos gerenciais e dos visionários. Os estratégicos sonham e tentam concretizar seus sonhos, sendo uma combinação do líder gerencial, que nunca pára para sonhar, e do visionário, que apenas sonha. Um líder estratégico provavelmente criará mais valor que a combinação de um líder visionário e de um gerencial. Os gerenciais buscam a estabilidade financeira da organização em curto prazo. Conseqüentemente, mantêm o status quo e não investem em inovações que possam mudar e aumentar os recursos da organização em longo prazo. Os líderes visionários procuram a viabilidade em longo prazo da organização, querem mudar e inovar, a fim de criar valor em longo prazo. A integração desses dois tipos de li- derança pode criar uma equipe de dois ou mais indivíduos que possa exercer liderança estratégica e criar valor para a organização. Contudo, um só indivíduo que combine, em sinergia, as qualidades de um visionário e de um gerencial realizará o máximo de criação de valor para a sua organização (ver Figura 3).

Os líderes estratégicos destacam o comportamento ético (Ireland e Hitt, 1999). São raros na maioria das organizações. Supervisionam responsabilidades operacionais rotineiras e estratégicas em longo prazo (Hambrick, 1989; Schendel, 1989). Formulam e implementam estratégias para impacto imediato e preservação de metas de longo prazo a fim de aumentar a evolução, a sobrevivência e a viabilidade organizacionais. Usam controles estratégicos e financeiros, enfatizando o estratégico (Hoskisson e Hitt, 1994). As expectativas que têm em relação à performance de seus superiores, pares, subordinados e deles próprios são grandes e otimistas. Alternam o uso de conhecimento explícito e tácito em relação ao indivíduo e à organização (Nonaka, 1994; Nonaka e Takeuchi, 1995) e adotam padrões de pensamento linear e não linear. Por fim, acreditam na adoção de estratégia, isto é, suas decisões estratégicas fazem diferença na sua organização, e isso afeta os ambientes externo e interno da organização (Trigg, 1996; Child, 1972; Mintzberg et al., 1998).

Os líderes estratégicos gerenciam o paradoxo criado pelos modelos de liderança visionária e gerencial. Valem-se de metáforas, analogias e modelos para permitir a justaposição de conceitos aparentemente contraditórios, definindo limites de coexistência mútua. Orientam o processo de geração de conhecimento, incentivando a capacidade de integrar conhecimentos tácitos e explícitos individuais, grupais e organizacionais para criar inovações organizacionais (Nonaka e

Figura 2 - Um continuum duplo das lideranças gerencial, visionária e estratégica

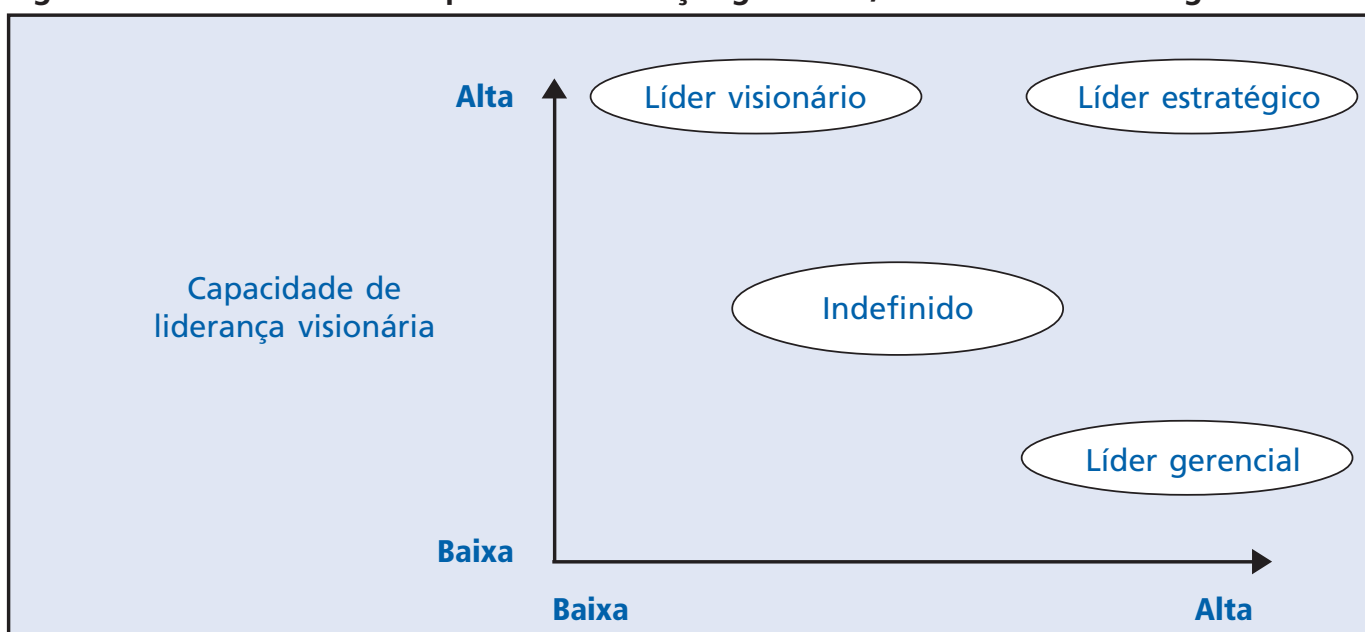

Capacidade de liderança gerencial 
Takeuchi, 1995; Kogut e Zander, 1992; Sherman e Rowe, 1996) e tecnológicas, a fim de melhorar a performance futura.

As organizações precisam deixar um grupo coeso

\section{LÍDERES ESTRATÉGICOS TÊM}

\section{EXPECTATIVAS GRANDES E OTIMISTAS}

\section{EM RELAÇÃO À PERFORMANCE}

\section{DE SEUS SUPERIORES, PARES,}

\section{SUBORDINADOS E DELES PRÓPRIOS.}

de gerentes desenvolver as habilidades necessárias ao exercício da liderança estratégica (Mintzberg, 1975), isto é, líderes gerenciais devem mostrar-se tolerantes em relação aos líderes visionários e estratégicos quando estes criam o caos, acabam com a ordem, correm riscos e até quando, sem querer, destroem coisas importantes para os líderes gerenciais. Por sua vez, os líderes estratégicos precisam entender o que os visionários e os gerenciais podem trazer para a organização e tirar proveito das habilidades e do conhecimento de ambos.

\section{RESTRIÇÕES NA LIDERANÇA ESTRATÉGICA}

Infelizmente, muitas organizações reprimem a liderança estratégica. Uma delas é o Estado (House, 1999), cujo processo de criação de valor deve ser entendido. O Estado tem a tarefa de criar valor em termos sociais. Isso significa que os governos são responsáveis pela eficiência da produção e da alocação das economias como um todo, pelo nível de emprego e pela conquista de um padrão de vida melhor (Barney, 1997). Com certeza, culpamos o governo ou damos crédito a ele se nosso padrão de vida piora ou melhora. Podemos inferir, portanto, que usamos nosso padrão de vida como uma medida de criação de valor.

Se analisarmos o Estado utilizando o conhecimento de estudos organizacionais, veremos que alguns fatores que afetam as organizações também afetam os governos. Governos competem por recursos da mesma forma que as organizações. Às vezes, acredita-se que as instituições governamentais sejam como monopólios, com poder de impor sua vontade à população. Contudo, o Estado compete com outras organizações por recursos humanos e com outras instâncias por impostos pagos pelos eleitores e por novos investimentos. Infelizmente, alguns governos também crescem e diversificam-se. Esse alto nível de diversificação, aliado ao enorme volume da dívida de muitos governos estaduais, municipais e federais e à prestação de contas do gasto com campanha eleitoral, a cada quatro anos, força os governos a usar controles financeiros e privamnos de indicadores estratégicos.

Isso obriga os líderes estratégicos potenciais a adotar um dos seguintes procedimentos: exercer somente a liderança gerencial, deixar a organização ou enfrentar o sistema, o que força o uso da energia estratégica que eles deveriam empregar na liderança e no gerenciamento da organização. Pessoas que trabalham para o Governo têm a capacidade de serem líderes visionários e estratégicos, mas a natureza do Governo impede que exerçam tais estilos de liderança.

Um sociólogo que trabalhou para a prefeitura de um município canadense relatou o seguinte sobre o que os líderes visionários criticam no governo (House, 1999): "A organização dos serviços públicos de Newfoundland e de Labrador é muito burocrática e hierárquica. Há um lugar para cada pessoa e cada uma delas deve saber seu devido lugar. As pessoas comunicam-se hierarquicamente: do funcionário para o gerente, para o diretor, para o assistente do vice-ministro, para o vice-ministro e, possivelmente, para o ministro e vice-versa. Muito se perde e muda de sentido durante esse processo, geralmente lento. Não é surpresa que os cidadãos e os grupos empresariais que têm o governo como 'cliente' reclamem da burocracia, tanto do excesso de papelada quanto do excesso de hierarquia. Tal sistema não está adaptado para lidar com mudanças. Quando uma mudança é necessária - e os altos funcionários reconhecem que ela é vital -, preferem que ocorra de forma lenta e sob o seu controle e direção. Esses funcionários são naturalmente céticos quanto aos primeiros-ministros, ministros e outros órgãos que queiram dar início a um grande número de mudanças em diferentes áreas em um curto período e também resistentes a eles. Esse sistema também tende a selecionar e moldar certos tipos de personalidade para o sucesso profissional. Valorizam-se confiança, perseverança e lealdade em lugar da criatividade, espírito de inovação e pensamento crítico. Aqueles que não se enquadram nesse modelo ficam estagnados, deixam o cargo ou são forçados a demitir-se. Os criativos são elogiados de maneira sarcástica 'Ele é esperto, mas não consegue gerenciar pessoas' ou 'Ela tem ótimas idéias, mas não pensa antes de falar'.'

É possível haver liderança estratégica em organizações desse tipo? A resposta é positiva, se houver duas condições muito difíceis de serem impostas: autonomia e proteção. Se um grupo de altos executivos prover autonomia a um grupo de gerentes de divisões, podemos ter uma liderança estratégica. Infelizmente, à medida que essa pequena parte da organização tornase bem-sucedida e obtém visibilidade, uma vez que 
passa a correr riscos e a enfrentar a burocracia, tornase muito mais difícil manter a autonomia e protegê-la da liderança gerencial da organização. Isso geralmente ocorre quando a liderança gerencial passa a controlar financeira e burocraticamente a organização.

\section{CRIAÇÃO DE VALOR E LIDERANÇA}

\section{Criação de valor e liderança gerencial}

Líderes gerenciais manterão, na melhor das hipóteses, o nível de valor gerado no passado; mas, com o tempo, podem destruir lentamente esse valor. Isso significa que o conselho de administração, o presidente e os principais executivos, responsáveis pelos ativos, estarão somente criando o valor que os proprietários desses bens esperavam que criassem (Barney, 1997). Esse fato é ilustrado na Figura 3 pela parte superior da seta próxima à elipse dos líderes gerenciais. Infelizmente, em organizações comandadas por líderes gerenciais, somente o controle financeiro é exercido, o que leva à inibição da criatividade e da inovação e a performances inferiores à média em longo prazo. Há pessoas criativas e inovadoras nessas organizações. É difícil, contudo, demonstrar essas características em tais ambientes. O baixo nível de performance é ilustrado pela parte inferior da seta próxima à elipse dos líderes gerenciais na Figura 3.

Este artigo já sugeriu que organizações diversificadas com negócios não relacionados comandadas por líderes gerenciais obtêm, no máximo, retornos equiva- lentes à média dos retornos e atingem apenas performances médias. Infelizmente, outros tipos de organização, tais como monopólios com preços regulados e organizações diversificadas com negócios relacionados, podem obter somente performance média ou inferior à média. Monopólios com preços regulados provavelmente desenvolverão liderança gerencial, pois são controlados financeiramente por seus reguladores, cujo único propósito é garantir uma taxa de retorno preestabelecida, a fim de manter a receita em um nível apropriado e satisfazer os consumidores. Algumas organizações diversificadas com vários negócios relacionados desenvolvem apenas liderança gerencial ou até uma liderança não satisfatória (baixa em ambos os continua de liderança gerencial e visionária). Alguns exemplos dessas empresas compreendem Kmart, Apple Computer, durante a ausência de Stephen Jobs, USX U.S. Steel Group e Digital Equipment Corp. De 1988 a 1997, o VAM do Kmart caiu de US\$ 0,837 bilhão para US\$ 2,257 bilhões negativos - uma desvalorização de US\$ 3,094 bilhões no patrimônio dos acionistas. Durante o mesmo período, a Apple desvalorizou o patrimônio dos acionistas em US\$ 4,85 bilhões, pois seu VAM caiu de US\$ 3,261 para US\$ 1,594 bilhão negativo (Walbert, 1995; Ross, 1996, 1998).

\section{Criação de valor e liderança visionária}

Os líderes visionários podem ou não criar valor. Se o fizerem, exercerão um estilo de liderança raro e difícil de ser copiado por outras organizações. Infelizmente, alguns visionários capazes de criar valor não têm

\section{Figura 3 - Criação de valor e lideranças gerencial, visionária e estratégica}

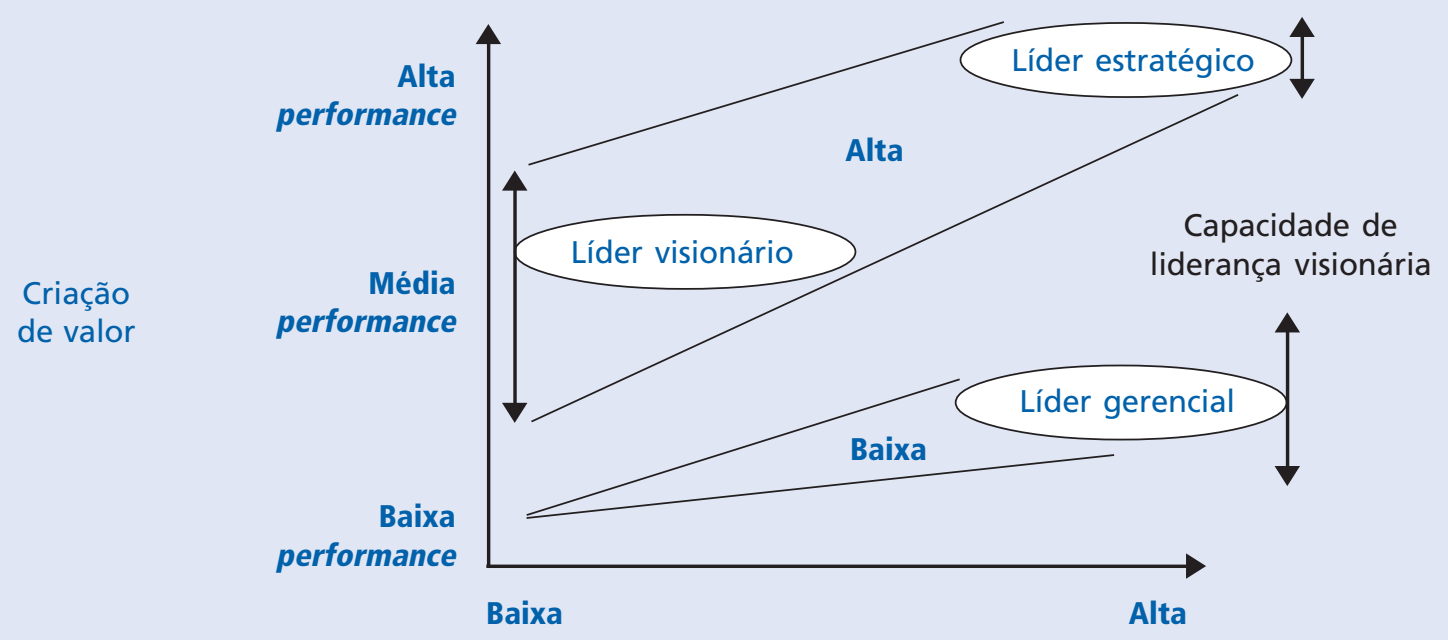

Capacidade de liderança gerencial

Nota: As setas verticais representam os efeitos diferenciais dos tipos de liderança na criação de valor. 
apoio de suas organizações com estruturas, controles e recompensas adequados (Barney, 1997). Essas organizações provavelmente vão alcançar uma performance inferior à média.

A liderança visionária é o estilo mais difícil de avaliar com relação à performance. Como ilustrado na Figura 3, visionários têm potencial para variar na escala da performance - de inferior à média para superior à média. $\mathrm{O}$ principal risco consiste em que podem atingir uma performance inferior à média mais rapidamente do que os líderes gerenciais. Stephen Jobs, o fundador visionário da Apple, foi obrigado a

\section{Pessoas que trabalham Para}

\section{O GOVERNO TÊM A CAPACIDADE}

DE SEREM LÍDERES VISIONÁRIOS E

\section{ESTRATÉGICOS, MAS A NATUREZA DO GOVERNO IMPEDE QUE EXERÇAM}

\section{TAIS ESTILOS DE LIDERANÇA.}

deixar a empresa devido à baixa performance. Anita Roddick, por muito tempo executiva principal da The Body Shop, foi forçada a renunciar, porque seu marido, Gordon, um líder gerencial, demitiu-se da organização e sua liderança visionária sozinha não pôde sustentar o nível de performance exigido pelos investidores. Michael Cowpland, executivo principal da Corel no Canadá, é descrito como um visionário, e a Corel tem apresentado problemas com a criação de valor por muitos anos, o que fez com que ele se afastasse em agosto de 2000. Por outro lado, visionários aliados a líderes gerenciais podem atingir uma performance superior à média. Dois exemplos são Thomas Watson Jr. (líder visionário) e Al William (líder gerencial), seu diretor financeiro na IBM de 1956 a 1970 (Watson Jr. e Petre, 1990).

\section{Criação de valor e liderança estratégica}

Como os líderes estratégicos estão preocupados com a viabilidade futura e a estabilidade financeira atual da organização, tomam decisões que maximizam o retorno sobre o investimento e, portanto, criam valor para sua organização (ver Figura 3).

Durante toda a década de 90 , nenhuma outra dupla de executivos exemplificou tão bem a criação de valor quanto Jack Welch e Robert Goizueta. Tanto a GE como a Coca-Cola se alternaram ocupando primeiro e segundo lugares no ranking de VAM de 1992 a 1998 (Walbert, 1995; Ross, 1996, 1997, 1998, 1999).
A Coca-Cola obteve um retorno de capital $24 \%$ maior do que o custo do capital. O que fizeram os dois executivos principais durante esse período? Ambos fizeram com que suas empresas se reconcentrassem para recuperar o controle estratégico. Acreditaram que suas atitudes afetavam as empresas e determinavam o que ocorria nos respectivos setores em que atuavam. Welch e Goizueta buscaram, implacavelmente, reduzir o efeito repressor da burocracia sobre a criatividade e a inovação. Ambos se mostraram insensíveis quanto ao passado a fim de manifestar respeito adequado pelo futuro. Acreditavam em mudanças revolucionárias, e não evolutivas. Muitos ficaram surpresos com a rapidez com que Welch mudou a GE. Já Welch ficou espantado com o tempo que isso demorou a acontecer. Seus valores podem ser resumidos da seguinte forma: entrem nos negócios certos aqueles que têm potencial de crescimento e reagem rapidamente a mudanças e tirem o máximo do capital investido. Esses valores são um exemplo de liderança estratégica (A conversation, 1995; Sellers, 1996; Morris, 1995).

A liderança estratégica não é apenas para gerentes profissionais indicados para comandar empresas. Tomemos como exemplo dois empreendedores que fizeram diferença em suas empresas e setores. O primeiro é Konosuke Matsushita, fundador e ex-diretor executivo da Matsushita Electric, que obteve US\$ 49,5 bilhões em crescimento de receita, o maior aumento do século 20 no mundo empresarial. Em seguida,vem Soichiro Honda, com um crescimento de US\$35,5 bilhões, e o Wal-Mart, de Sam Walton, com US\$ 35 bilhões. Matsushita foi um visionário que exigia crescimento de receita, porém com aumento maior do lucro. Ele dizia à sua alta gerência que queria que a receita quadruplicasse e os lucros mais que quadruplicassem em cinco anos. Essa meta, contudo, foi atingida em quatro anos (Kotter, 1997). Ele ateve-se a criar produtos que agregassem maiores valores que o esperado por seus clientes. Porém sempre exigiu que tais valores fossem criados com certo lucro para a empresa.

O segundo empreendedor é Bob Kierlin (Teitelbaum, 1997), executivo principal da Fastenal, empresa que comercializa porcas e parafusos. Seu estilo de liderança é caracterizado pela delegação de poderes, participação, igualitarismo, limitação salarial (ele ganha US\$ 120 mil ao ano) e política de promoção dentro da empresa (Conger, 1989; Pfeffer, 1995). Contudo, incentiva veementemente um crescimento de receita e lucro, o que tem beneficiado funcionários, clientes e acionistas. Em 1988, o VAM da Fastenal era de US\$ 0,077 bilhão, já, em 1996, era de US\$1,609 bilhão, uma valorização de US $\$ 1,53$ bilhão. Kierlin criou a Fastenal em 1967, por não estar satisfeito com a burocracia da IBM. 
O Wal-Mart e a Coca-Cola são dois outros exemplos de empresas interessantes sob a perspectiva da liderança estratégica. De 1988 a 1992, o patrimônio dos acionistas do Wal-Mart teve uma valorização de US\$ 50 bilhões sob a liderança de Sam Walton. Em contrapartida, de 1992 a 1996, o patrimônio dos acionistas sofreu uma desvalorização de US\$ 30 bilhões sob a liderança de David Glass. De 1996 a 1997, o Wal-Mart retomou o crescimento e encerrou 1997 com um VAM de US\$ 69,7 bilhões. Portanto, de 1992 a 1997, o Wal-Mart teve uma valorização de US\$ 5,7 bilhões, cerca de um décimo do que Sam Walton gerou no mesmo período de cinco anos. Porém, ao final de 1998, o VAM do Wal-Mart era de US\$ 213 bilhões, saltando para o terceiro lugar do ranking de VAM, e, de 1992 a 1998, seu VAM teve uma valorização de US\$ 143 bilhões.

David Glass é o líder estratégico que foi Sam Walton? É muito cedo para dizer. Certamente, a perspectiva de Walton era parecida com a de Matsushita. Walton queria melhorar a qualidade de vida de seus clientes e funcionários. Ele afirmou: "Nós melhoramos a qualidade de vida de nossos clientes, por quem economizamos bilhões de dólares, e de nossos representantes, com quem dividimos lucros" (Walton e Huey, 1992). Ele queria comercializar a maior quantidade de mercadorias ao menor preço possível.

Sob a liderança de Goizueta, a Coca-Cola subiu no ranking de VAM da sétima posição em 1988 para a primeira posição em 1994, permanecendo em primeiro lugar até 1996. Em 1997, ano em que Goizueta faleceu, a Coca-Cola caiu para o segundo lugar e, em 1998, para o nono. O VAM absoluto da Coca-Cola ainda estava melhorando sob a liderança de Doug Ivester e, mesmo assim, encontrava-se numa posição bem melhor do que a da Pepsico, sua maior concorrente. Porém, Ivester não conseguiu valorizar o VAM da Coca-Cola na mesma proporção que Goizueta; conseqüentemente, afastou-se em abril de 2000 (Creenwald, 1999).

Todos esses líderes estratégicos acreditavam que suas decisões poderiam afetar suas empresas e ambientes de trabalho. Eles esforçaram-se para alcançar seus objetivos influenciando liderados e garantindo que seus objetivos fossem atingidos da melhor maneira possível para os funcionários, clientes e acionistas (Walton e Huey, 1992). No entanto, seus objetivos deveriam ser atingidos sem que a organização fosse arruinada financeiramente em curto prazo. Goizueta procurou, incansavelmente, um retorno que superasse o custo do capital da Coca-Cola. Esses líderes administraram o paradoxo de investir estrategicamente em seus funcionários, em promoção, em $\mathrm{P} \& \mathrm{D}$ e em equipamento, ao mesmo tempo em que garantiam que suas organizações fossem financeiramente estáveis em curto prazo.

\section{O PARADOXO: LIDERAR E GERENCIAR}

É possível criar valor em organizações nas quais a liderança estratégica é exercida porque os líderes estratégicos investem adequadamente em viabilidade futura, ao mesmo tempo em que mantêm a atual estabilidade financeira em um nível apropriado. Eles influenciam um grupo suficiente de gerentes e funcionários para tomar, de forma voluntária e rotineira, decisões que aumentem a viabilidade futura e a estabilidade atual da organização.

\section{Muitos ficARAM SURPRESOS}

\section{COM A RAPIDEZ COM QUE WELCH Mudou a GE. JÁ WelCh FICOU ESPANTADO COM O TEMPO QUE}

\section{ISSO DEMOROU A ACONTECER.}

Infelizmente, grandes organizações diversificadas em negócios não relacionados treinam seus funcionários implícita e explicitamente para serem líderes gerenciais. Tal conduta não está errada, mas, quando esse tipo de liderança não permite o surgimento das lideranças estratégica e visionária, a organização será prejudicada em longo prazo. A natureza de algumas organizações impossibilita o surgimento das lideranças estratégica e visionária. Hoskisson e Hitt (1994, cap. 4 e 11) referem-se a esse fenômeno como perda de controle estratégico. Isso ocorre em governos, universidades (públicas ou privadas) e negócios em que há uma diversificação inadequada.

Um estudo do governo canadense (Baldwin et al., 1997) concluiu que duas das razões mais importantes para que empresas de pequeno a médio portes requeiram falência são as habilidades gerenciais precárias e estruturas de capital imperfeitas, resultantes de pressões institucionais ou inexperiência gerencial. Os autores da pesquisa argumentam que gerentes de pequenas empresas precisam ser treinados em administração geral e habilidades de gerenciamento financeiro e que as lideranças visionária e gerencial são necessárias tanto em pequenas e médias empresas quanto em grandes empresas. Dollinger (1999) advoga que empresários são arquitetos organizacionais que criam empreendimentos para materializar suas visões. Afirma, ainda, que os piores problemas para os empreendedores são a falta de habilidades gerenciais e a dificuldade para elaborar um plano de negócios que detalhe os riscos do novo negócio. De acordo com essa pesquisa, podemos argumentar que pequenas em- 
presas sofrem mais com a falta de liderança gerenci$\mathrm{al}$, enquanto grandes empresas sofrem com a falta de liderança visionária, principalmente se perderam o controle estratégico porque se diversificaram demais. Está claro que pequenas, médias e grandes organizações devem favorecer a existência de lideranças estratégicas entre os membros da alta gerência, da gerência intermediária e entre os gerentes juniores (ver Tichy e Cohen, 1997).

Um líder estratégico cria desordem, comete erros $\mathrm{e}$, às vezes, é repreendido por seus chefes e subordinados, precisando até desculpar-se com os funcionários por ter criado muita desordem sem que eles estivessem preparados para isso. Entretanto, as recompensas valem a pena, visto que as pessoas que trabalham com esse líder apresentam um aumento em termos de energia e produtividade, realizando mais tarefas em um tempo menor. Eles têm mais prazer no trabalho, tornando- se mais criativos, inovadores e mais propensos a correr riscos, pois sabem que isso aumentará a viabilidade em longo prazo.

Lidar com o paradoxo de liderar e gerenciar é difícil, mas é possível para uma massa crítica em organizações que não perderam o controle estratégico. Os executivos dessas organizações devem começar a ver-se como líderes estratégicos que necessitam aceitar e unir líderes visionários e gerenciais. Devem combater as influências coercitivas do controle financeiro e lutar pelo exercício dos controles estratégicos e financeiros, com ênfase nos estratégicos. Devem entender os conceitos de conhecimento tácito e explícito, de pensamento linear e não linear e perceber como podem integrá-los para que a organização se beneficie. As recompensas freqüentemente serão a criação de valor e a performance superior à média tanto nas organizações recém-criadas como nas já estabelecidas. $\bigcirc$

NOTAS

0 autor gostaria de agradecer aos muitos alunos de sua disciplina "Liderança Estratégica" da Royal Roads University, Victoria, BC, e da Memorial University de Newfoundland, Canadá, por terem colaborado na elaboração das idéias apresentadas neste artigo. Gostaria também de agradecer os inúmeros comentários construtivos que recebeu de profissionais na 1988
Conference of Newfoundland and Labrador Employer's Council, na 1997 Conference of the Atlantic Provinces Economic Council e do Senior Management Group em 1999 da Xwave Solutions, Newfoundland Business Unit. Por fim, 0 autor gostaria de agradecer a Fay Rowe, James O'Brien e aos três avaliadores anônimos e co-editores convidados que teceram comentários construtivos.

\section{REFERÊNCIAS BIBLIOGRÁFICAS}

A CONVERSATION with Robert Goizueta and Jack Welch: the wealth builders. Fortune, p. 96-102, 11 Dec. 1995

BALDWIN, J., GRAY, T., JOHNSON, J. et al. Failing concerns: business bankruptcy in Canada. Ottawa : Statistics Canada, Nov. 1997. Catalogue No. 6l-525XPE.

BARNEY, J. B. Gaining and sustaining competitive advantage. New York : Addison-Wesley Publishing Company, 1997.

BASS, B. M. Leadership and performance beyond expectations. New York : The Free Press, 1985.

CHATTERJEE, S., LUBATKIN, M. H., SCHULZE, W. S. Toward a strategic theory of risk premium: moving beyond CAPM. Academy of Management Review, v. 24, n. 3, p. 556-567, 1999.

CHEN, C. C., MEINDL, J. R. The construction of leadership images in the popular press: the case of Donald Burr and People Express. Administrative Science Quarterly, v. 36, p. 521-551, 1991.
CHILD, J. Organizational structure, environment and performance: the role of strategic choice. Sociology, v. 6, p. 1-22, 1972.

CONGER, J. Leadership: the art of empowering others. The Academy of Management Executive, v. 3, n. 1, p. $17-24,1989$.

CONGER, J. Inspiring others: the language of leadership. The Academy of Management Executive, v. 5, n. 1, p. 31-45, 1991.

CREENWALD, J. Spring a leak: five lessons from a Corporate kings downfall. Time, p. 46-48, 20 Dec. 1999.

DOLLINGER, M. J. Entrepreneurship: strategies and resources. 2. ed. Upper Saddle River, NJ : Prentice Hall, 1999.

EVANS, R. Hollow the leader. Report on Business, p. 56-63, Nov. 1997

EVERED, Li. So what is strategy? Monterey : Naval Postgraduate School, 1980. Working paper.
Artigo publicado originalmente na The Academy of Management Executive, v. 15, n. 1, p. 81-94, Feb. 2001.

GARDNER, W. L., AVOLIO, B. J. The charismatic relationship: a dramaturgical perspective. Academy of Management Review, v. 23, n. 1, p. 32-58, 1998.

HAMBRICK, D. Guest's editor's introduction: putting top managers back in the strategic picture. Strategic Management Journal, v. 10, p. 5-15, 1989. Special issue.

HILL, C. W. L., HOSKISSON, R. E. Strategy and structure in the multiproduct firm. Academy of Management Review, v. 12, n. 2, p. 331-341, 1987.

HILL, L., WETLAUFER, S. Leadership when there is no one to ask: an interview with ENI's Franco Bernabe. Harvard Business Review, p. 80-96, Julyl Aug. 1998.

HITT, M. A., IRELAND, R. D., HOSKISSON, R. E. Strategic management: competitiveness and globalization. 4. ed. Cincinnati : South-Western College Publishing Company, 2001. Cap. 1. 
HOSKISSON, R. E., HITT, M. A. Downscoping: taming the diversified firm. New York : Oxford University Press, 1994.

HOSMER, L. T. The importance of strategic leadership. Journal of Business Strategy, v. 3, n. 2 p. 47-57, Fall 1982

HOUSE, J. D. Against the tide: battling for economic renewal in Newfoundland and Labrador. Toronto : University of Toronto Press, 1999.

IRELAND, R. D., HITT, M. A. Achieving and maintaining strategic competitiveness in the 21 st century: the role of strategic leadership. The Academy of Management Executive, v. 13, n. 1, p. 43-57, 1999

ITAMI, H. Mobilizing invisible assets. Cambridge, MA Harvard University Press, 1987.

KERR, S., JERMIER, J. M. Substitutes for leadership their meaning and measurement. Organizational Behavior and Human Performance, v. 22, p. 735403, 1978

KOGUT, B., ZANDER, U. Knowledge of the firm, combinative abilities, and the replication of technology. Organization Science, v. 3, p. 383 $397,1992$.

KOTTER, J. P. What leaders really do. Harvard Business Review, May/June 1990.

KOTTER, J. P. Matsushita leadership. New York : Free Press, 1997.

KOTTER, J., HESKETT, J. Corporate culture and performance. New York: The Free Press, 1992

MEINDL, J. R. On leadership: an alternative to the conventional wisdom. In: STAW, B. M., CUMMINGS L. L. (Eds.). Research in Organizational Behavior. Greenwich, CT : JAI Press, 1990. V. 12, p. 159-203.

MEINDL, J. R., EHRLICH, S. B., DUKERICH, J. M. The romance of leadership. Administrative Science Quarterly, v. 30, p. 78-102, 1985.

MINTZBERG, $\mathrm{H}$. The nature of managerial work. New York : Harper and Row, 1973. Cap. 15-17.

MINTZBERG, H. The manager's job: folklore and fact. Harvard Business Review, July/Aug. 1975.

MINTZBERG, H. Crafting strategy. Harvard Business Review, July/Aug.1987a.
MINTZBERG, H. Five Ps for strategy. California Management Review, Fall 1987b.

MINTZBERG, H., AHLSTRAND, B., LAMPEL, J. Strategy safari. New York: The Free Press, 1998.

MINTZBERG, H., QUINN, J. B. The strategy process: concepts, contexts, cases. 3. ed. Upper Saddle River NJ : Prentice Hall, 1996.

MORRIS, B. Robert Goizueta and Jack Welch: the wealth builders, Fortune, p. 80-94, 11 Dec. 1995

NATHAN, M. What is organizational vision? Ask chief executives. The Academy of Management Executive, v. 10, n. 1, p. $82-83,1996$.

NELSON, R., WINTER, S. An evolutionary theory of economic change. Cambridge, MA : Belknap Press, 1982.

NONAKA, I. A dynamic theory of organizationa knowledge creation. Organization Science, v. 5, n. 1 p. 14-37, 1994

NONAKA, I., TAKEUCHI, H. The knowledge creating company. New York: Oxford University Press, 1995.

OUCHI, W. O., MAGUIRE, M. Organizational control: two functions. Administrative Science Quarterly, v. 20, p. 559 569, 1975.

PFEFFER I. Producing sustainable competitive advantage through the effective management of people. The Academy of Management Executive, v. 9 n. 1 , p. 55-72, 1995

POLANYI, M. The tacit dimension. Garden City, NY : Anchor, 1966.

QUINN, J. B. Strategies for change: logical incrementalism. Homewood, IL: Richard D. Irwin, 1980.

REED, R., DEFILLIPPI, R. J. Causal ambiguity barriers to imitation, and sustainable competitive advantage. Academy of Management Review, v. 15, p. 88-102, 1990

ROSS, I. The 1995 Stern Stewart Performance 1000 Journal of Applied Corporate Finance, v. 8, n. 4, p. 1 18 . Winter 1996

ROSS, I. The 1996 Stern Stewart Performance 1000. New York: Stern Stewart \& Co., 1997. p. 1-19.

ROSS, I. The 1997 Stern Stewart Performance 1000. Journal of Applied Corporate Finance, v. 10, n. 4, p. 116-128, Winter 1998
ROSS, I. The 1998 Stern Stewart Performance 1000. New York : Stern Stewart \& Co., 1999. p. 1-15.

SCHEIN, E. H. On dialogue, culture, and organizational learning. Organizational Dynamics, v. 22, n. 2, p. 4051,1993.

SCHENDEL, D. Introduction to the special issue on strategic leadership. Strategic Management Journal, v. 10, p. 1-3, 1989. Special issue.

SCHULTZ, H., YANG, D. J. Pour your heart into it: how Starbucks built a company one cup at a time. New York: Hyperion, 1997. p. 181.

SELLERS, P. How Coke is kicking Pepsi's can. Fortune, p. 70-84, 28 Oct. 1996.

SHERMAN, S., ROWE, W. G. Leadership and strategic value: a resource-based typology. Proceedings of the Texas Conference on Organizations, Mar. 1996.

SOOKLAL, L. The leader as a broaker of dreams. Human Relations, v. 44, n. 8, p. 833-856, 1991.

STARBUCKS: making values pay. Fortune, p. 261272, 29 Sep. 1997.

TEITELBAUM, R. Who is Bob Kierlin - and why is he so successful? Fortune, p. 245-248, 8 Dec. 1997 ,

TICHY, N. M., COHEN, E. The leadership engine: how winning companies build leaders at every level. New York: HarperCollins, 1997

TRIGG, R. Ideas of human nature: an historical introduction. Cambridge, MA : Blackwell Publishers, 1996.

WALBERT, L. The 1994 Stern Stewart Performance 1000. Journal of Applied Corporate Finance, v. 7, n. 4, p. 104-118, Winter 1995.

WALTON, S., HUEY, J. Sam Walton: made in America - my story. New York : Doubleday, 1992.

WATSON JR., T. J., PETRE, P. Father son \& Co:: my life at IBM and beyond. New York: Bantam Books, 1990

YUKL, G. Leadership in organizations, 3. ed. Toronto : Prentice Hall, 1994.

ZALEZNIK, A. Managers and leaders: are they different? Harvard Business Review, May/June 1977.

ZALEZNIK, A. The leadership gap. The Academy of Management Executive, v. 4, n. 1, p. 7-22,1990. 